\title{
Influence of Preemptive Analgesia with Oxycodone Hydrochloride on Stress Hormone Level of Geriatric Patients undergoing Gastrointestinal Surgery
}

\author{
Jinli Zhang ${ }^{1}$, Yixuan Zhang ${ }^{2}$, Hongli Yan ${ }^{3}$ and Ke Zhang ${ }^{3}$ \\ ${ }^{1}$ Department of Anesthesiology, Baoding First Central Hospital, Baoding, Hebei, P. R. China \\ ${ }^{2}$ Fourth Clinical Institute, Class 2016, Xinxiang Medical University, Xinxiang, Henan, P. R. China \\ ${ }^{3}$ Department of Scientific Research, Affiliated Hospital of Hebei University, Baoding, Hebei, P. R. China
}

\begin{abstract}
Objective: To determine the influence of preemptive analgesia with oxycodone hydrochloride on stress hormone level of geriatric patients undergoing gastrointestinal surgery, and evaluate the analgesic effect.

Study Design: Rrandomised controlled trial.

Place and Duration of Study: Department of Anaesthesiology, Baoding First Central Hospital, from January to December 2017.

Methodology: Geriatric patients who were to undergo gastrointestinal surgery were classified into observation group and control group of 30 patients each. For the observation group, intravenous injection of $0.1 \mathrm{mg} / \mathrm{kg}$ oxycodone hydrochloride injection was conducted 10 mins before anesthesia induction. For the control group, intravenous injection of $10 \mathrm{ml}$ normal saline was conducted. Eight $\mathrm{ml}$ of venous blood was drawn 10 mins before injection (T0), after operation (T1), 2 hours after operation (T2), 6 hours after operation (T3), and 24 hours after operation (T4). Serum concentration of cortisol, epinephrine, noradrenaline was determined after the completion of surgery (T1), 2-hour after surgery (T2), 6-hour after surgery (t3) and 24-hour after sutrgery (T4). for both groups. Visual analogue scale (VAS) score was used for assessment of pain when the surgery was completed; and after the surgery, was compared for both groups.
\end{abstract}

Results: Serum concentrations of epinephrine and noradrenaline in observation group were significantly reduced at T1 and T2 ( $p$ $<0.05$ ), and serum concentrations of cortisol and glucose were significantly reduced at T1, T2 and T3 ( $p<0.05)$. At 2 and 6 -hours after operation, the VAS score was significantly lower than that of the control group $(p<0.05)$.

Conclusion: Giving oxycodone hydrochloride to geriatric patients receiving gastrointestinal surgery can reduce stress hormone release in the postoperative period, and can facilitate postoperative recovery.

Key Words: Sold, Gastrointestinal surgery, Oxycodone hydrochloride, Preemptive analgesia, Stress response.

How to cite this article: Zhang J, Zhang Y, Yan H, Zhang K. Influence of Preemptive Analgesia with Oxycodone Hydrochloride on Stress Hormone Level of Geriatric Patients undergoing Gastrointestinal Surgery. J Coll Physicians Surg Pak 2020; 30(05):476-479. DOI: https://doi.org/10.29271/jcpsp.2020.05.476.

\section{INTRODUCTION}

According to international regulations, people over the age of 65 are defined as the elderly or geriatric; in China, citizens over the age of 60 are defined as the elderly or geriatric. Physiological functions of geriatric patients generally present degenerative changes, and their endurance capacity also declines. Besides, diabetes and other system diseases are often accompanied, which severely affects patients' cardiopulmonary compensationfunction. ${ }^{1-3}$

When gastrointestinal disease is treated with open surgery, the incision size is large, and postoperative pain may be severe, thus seriously affecting patients' circulation, breathing, internal

Correspondence to: Hongli Yan, Department of Scientific Research, Affiliated Hospital of Hebei University, Baoding, Hebei 071000, P. R. China

E-mail: cyiayy@sina.com

Received: June 03, 2019; Revised: February 21, 2020;

Accepted: June 01, 2020

DOI: https://doi.org/10.29271/jcpsp.2020.05.476 secretion, metabolism, gastrointestinal function recovery and wound healing, etc. Besides, a series of inflammatory and stress responses are initiated. ${ }^{4} \mathrm{Oxycodone}$ is a common double agonist of opium $k$ receptor and $\mu$-receptor, and can hinder neurosensory pathway and reduce body sensitivity to harmful feeling so as to reach the purpose of postoperative analgesia, called preemptive analgesia. ${ }^{5}$

The aim of this study was to determine the effect of oxycodone hydrochloride for geriatric patients undergoing gastrointestinal surgery, on serum concentration changes of cortisol, epinephrine, norepinephrine and glucose after the surgery and postoperative analgesia.

\section{METHODOLOGY}

The study was approved by the Institutional Ethics Committee of Baoding First Central Hospital, and written informed consent was obtained from all participants.

General data of 60 patients, who received stomach, duodenum, colon and other intestinal tract surgeries under general anesthesia at Baoding First Central Hospital from January 2017 to 
December 2017, were collected. They were classified into an observation group and a control group of 30 cases each. Exclusion criteria were abnormal liver and kidney function before operation; history of coronary heart disease; severe hypertension, gastrointestinal ulcer; history of abuse of sleeping pills and narcotic drug. Those undergoing any surgery of stomach, duodenum, colon and other intestines were selected in this surgery group patients. They all signed the informed consent form. The sample size was calculated using the sample size formula of the repeated measurement data as follows:

$$
N=\frac{\left(Z_{(1-\alpha / 2)}+Z_{(1-\beta)}\right)^{2} \times \sigma^{2} \times 2[1+(T-1) \rho]}{v^{2} T}
$$

Where $(1-\beta)$ is the test efficiency, which is the value of the standard normal distribution ( $1-\alpha / 2)$ percentile. When $\alpha$ is 0.05 , then $Z 0.05 / 2=1.96$; is the standard normal distribution (1) - $\beta$ ) Percentile value, taking $\beta$ as $0.1, Z 0.1=1.28 ; \sigma$ is the mean standard deviation of outcome variables, $\rho$ is the cortisol relation coefficient between repeated measures, $T$ is the number offollowup measurements, and $v$ is the difference between the mean values of the outcome variables between the groups. According to the formula, the sample size of the five parts of cortisol, epinephrine, norepinephrine and glucose, and VAS was calculated, and the largest sample was 29. Therefore, the sample size of this study I was 30 .

For the observation group, intravenous injection of $0.1 \mathrm{mg} / \mathrm{kg}$ oxycodone hydrochloride injection was conducted 10 mins before anesthesiainduction. For the control group, intravenous injection of $10 \mathrm{ml}$ normal saline was conducted. Anesthesia induction: intravenous injection of $0.05 \mathrm{mg} / \mathrm{kg}$ midazolam, $4 \mathrm{ug} / \mathrm{kg}$ fentanyl, $2.0 \mathrm{ng} / \mathrm{ml}$ propofol or $0.2 \mathrm{mg} / \mathrm{kg}$ etomidate, and 0.9 $\mathrm{mg} / \mathrm{kg}$ rocuronium bromide was carried out for anesthesia induction. After consciousness and autonomous respiration disappeared, and the underjaw was flabby, trachea cannula was conducted. Intermittent mechanical positive pressure ventilation was carried out at tidal volume (VT) of $6-8 \mathrm{ml} / \mathrm{Kg}$, respiratory rate (RR) of 14-16 times / minute, oxygen flow of $1.5 \mathrm{ml} / \mathrm{Kg}$, respiratory ratio of $1: 2$, maintaining PET (Co2) $35-45 \mathrm{mmHg}$. During the surgery, $3-4 \mathrm{mg} / \mathrm{kg}$ propofol and Remifentanil $0.08-0.1 \mu \mathrm{g} /(\mathrm{Kg} /$ minute) were infused at the constant speed.

Eight $\mathrm{ml}$ of venous blood was drawn 10 mins before injection (T0), after the operation (T1), after 2 hours (T2), after 6 hours (T3), after 24 hours (T4);8ml venous blood was drawn at T0 (10 mins before injection), T1, T2, T3 and T4, and cortisol, epinephrine, norepinephrine and glucose values were measured. Visual analog scale (VAS) was used for pain assessment Score of the 2 groups when the surgery was completed, $2 \mathrm{~h}, 6 \mathrm{~h}, 12 \mathrm{~h}$ and $24 \mathrm{~h}$ after the surgery was evaluated. SPSS17.0 statistical package was used for data statistics and processing. Measurement data were expressed with $\mathrm{x} \pm \mathrm{s}$, and independent sample t test was used for inter-group comparison, frequency or percentage was used for counting data. $X^{2}$ test was used to compare enumeration data. $a=0.05$ was applied as the test level.

\section{RESULTS}

The patient's age was 60-75 (66.5 \pm 7.1$)$ years; gender was not limited, 49 males and 11 females; body weight was 50-77 (66.1 \pm 1.8 ) kg; 35 patients were ASA grade I and 25 patients were grade II. General information of both groups is shown in Table I.

General information comparison difference had no significance ( $p>0.05)$, are shown in Table II. The concentrations of epinephrine and norepinephrine in the observation group were significantly lower than those in the control group $(E P 1=0.001$, EP2 $=0.001$; $\mathrm{NP} 1=0.001 ; \mathrm{NP2}=0.001$ ); the concentrations of cortisol and glucose in the observation group were significantly lower than those in the control group $(C P 1=0.001, C P 2=0.001, C P 3=0.001$; $\mathrm{GP} 1=0.001, \mathrm{GP} 2=0.001, \mathrm{GP} 3=0.001)$. The VAS score of the observation group at the end of surgery, $2 \mathrm{~h}$ and $6 \mathrm{~h}$ after surgery was significantly lower than the control group ( $p 0$ $=0.001 ; p 1=0.001 ; p 2=0.001$ respectively), as shown in Table III.

Table I: General information statistics of patients $(n=60)$.

\begin{tabular}{|c|c|c|c|c|}
\hline & $\begin{array}{c}\text { Observation group } \\
(\mathbf{n}=\mathbf{3 0})\end{array}$ & $\begin{array}{c}\text { Control group } \\
(\mathbf{n}=\mathbf{3 0})\end{array}$ & $t / X^{2}$ & $\mathbf{p}$ \\
\hline $\begin{array}{l}\text { Gender } \\
\text { Male } \\
\text { Female }\end{array}$ & $\begin{array}{l}20(66.7 \%) \\
10(33.3 \%)\end{array}$ & $\begin{array}{l}19(63.3 \%) \\
11(36.7 \%)\end{array}$ & 0.073 & 0.787 \\
\hline Body mass (kg) & $66.1 \pm 1.8$ & $66.0 \pm 1.4$ & 0.240 & 0.811 \\
\hline $\begin{array}{l}\text { ASA grade } \\
\text { I } \\
\text { II }\end{array}$ & $\begin{array}{l}17(56.7 \%) \\
13(43.3 \%)\end{array}$ & $\begin{array}{l}18(60 \%) \\
12(40 \%)\end{array}$ & 0.069 & 0.793 \\
\hline $\begin{array}{l}\text { Type of surgery } \\
\text { (stomach / intestines) } \\
\text { Stomach } \\
\text { Intestines }\end{array}$ & $\begin{array}{c}8(26.7 \%) \\
22(73.3 \%)\end{array}$ & $\begin{array}{c}9(30 \%) \\
21(70 \%)\end{array}$ & 0.082 & 0.775 \\
\hline Duration of surgery (min) & $100.1 \pm 11.2$ & $98.9 \pm 12.9$ & 0.385 & 0.702 \\
\hline Intraoperative blood loss (ml) & $202.4 \pm 50.5$ & $196.9 \pm 58.9$ & 0.388 & 0.699 \\
\hline
\end{tabular}

\section{DISCUSSION}

All patients received a midline laparotomy incision, with potential for severe postoperative pain. Besides, the surgery involved visceral organs, and patients had visceralgia. The heart, liver, lung and kidney functions of senile patients degenerate, and their medicine metabolism function declines. The half-life period of medicine lengthens obviously. When the surgery and anesthesia further weaken various functions of body, patients' postoperative breathing, circulation and cognition function will be affected. ${ }^{6}$ Oxycodone hydrochloride mainly acts on the central nervous system and smooth muscle, and has definite analgesic effect on internal organs. Besides, it will not cause euphoria, gastrointestinal motility and respiratory depression. ${ }^{7-9}$ In recent years, it has been applied clinically through multiple ways, such as preemptive analgesia. Preemptive analgesia means that the anaesthetic is applied before the surgery to hinder neurosensory pathway and reduce body sensitivity to harmful feeling so as to reach the purpose of postoperative analgesia. ${ }^{10}$

When the body is suddenly subjected to strong harmful stimulation (such as trauma, operation, blood loss, infection, poisoning, hypoxia, etc.), the concentration of adrenocorticotropic hormone in the blood increases rapidly through the hypothalamus, and the massive secretion of glucocorticoid is called stress response. Moderate stress can make the body enhance the ability to resist all kinds of stimuli. However, overstimulation will damage internal environment of body, thus leading to the decrease in the bearing capacity of body. ${ }^{11}$ 
Table II: Comparison of serum cortisol, epinephrine, norepinephrine and glucose concentration of 2 groups ( $x \pm s)(n=60)$.

\begin{tabular}{|c|c|c|c|c|c|c|}
\hline Laboratory indicator & Group & Tо & T1 & T2 & T3 & T4 \\
\hline \multirow{2}{*}{ Cortisol (ng/ml) } & $\begin{array}{l}\text { Observation } \\
\text { group }\end{array}$ & $145.1 \pm 31.6$ & $154.7 \pm 28.8^{*}$ & $158.1 \pm 26.9 *$ & $156.9 \pm 29.1^{*}$ & $156.1 \pm 21.9$ \\
\hline & Control group & $151.2 \pm 28.1$ & $242.6 \pm 21.5^{\#}$ & $217.5 \pm 27.2^{\#}$ & $192.9 \pm 23.8^{\#}$ & $156.9 \pm 26.8$ \\
\hline $\mathrm{t}$ & & 0.790 & 13.396 & 8.255 & 5.245 & 0.127 \\
\hline$p$ & & 0.433 & 0.001 & 0.001 & 0.001 & 0.900 \\
\hline \multirow[t]{2}{*}{ Epinephrine (pg/ml) } & $\begin{array}{l}\text { Observation } \\
\text { group }\end{array}$ & $15.2 \pm 3.5$ & $16.0 \pm 3.4^{*}$ & $16.2 \pm 3.2^{*}$ & $15.2 \pm 3.5$ & $15.9 \pm 3.2$ \\
\hline & Control group & $14.8 \pm 4.1$ & $27.6 \pm 4.8^{\#}$ & $24.2 \pm 4.4^{\#}$ & $14.8 \pm 4.1$ & $15.8 \pm 3.5$ \\
\hline $\mathrm{t}$ & & 0.406 & 10.801 & 8.255 & 0.406 & 0.115 \\
\hline$p$ & & 0.686 & 0.001 & 0.001 & 0.686 & 0.908 \\
\hline \multirow{2}{*}{$\begin{array}{l}\text { Norepinephrine } \\
\text { (pg/ml) }\end{array}$} & $\begin{array}{l}\text { Observation } \\
\text { group }\end{array}$ & $344.2 \pm 98.6$ & $386.8 \pm 103.1 *$ & $381.9 \pm 92.7^{*}$ & $383.3 \pm 95.5$ & $359.1 \pm 102.1$ \\
\hline & Control group & $352.3 \pm 0.38$ & $479.1 \pm 108.1^{\#}$ & $461.3 \pm 101.2^{\#}$ & $428.5 \pm 99.1^{\#}$ & $358.7 \pm 101.2$ \\
\hline $\mathrm{t}$ & & 0.450 & 3.384 & 3.169 & 1.799 & 0.015 \\
\hline$p$ & & 0.654 & 0.001 & 0.002 & 0.077 & 0.988 \\
\hline \multirow[t]{2}{*}{ Glucose (mmol/L) } & $\begin{array}{l}\text { Observation } \\
\text { group }\end{array}$ & $5.5 \pm 0.5$ & $5.8 \pm 0.7^{*}$ & $5.6 \pm 0.4^{*}$ & $5.5 \pm 0.4 *$ & $5.4 \pm 0.5$ \\
\hline & Control group & $5.6 \pm 0.4$ & $7.9 \pm 0.8^{\#}$ & $7.8 \pm 0.7^{\#}$ & $7.1 \pm 0.7^{\#}$ & $5.5 \pm 0.6$ \\
\hline $\mathrm{t}$ & & 0.855 & 10.820 & 14.946 & 10.870 & 0.701 \\
\hline$p$ & & 0.396 & 0.001 & 0.001 & 0.001 & 0.486 \\
\hline
\end{tabular}

Table III: Postoperative pain scores of both groups (n=60).
\begin{tabular}{|l|c|c|c|c|c|c|}
\hline Group & No. & Completion of surgery & 2h after surgery & 6h after surgery & $\mathbf{1 2 h}$ after surgery & $\mathbf{2 4 h}$ after surgery \\
\hline Observation group & 30 & $4.3 \pm 0.8^{*}$ & $4.4 \pm 0.9 *$ & $4.6 \pm 1.5^{*}$ & $5.0 \pm 0.9$ & $4.5 \pm 0.9$ \\
\hline Control group & 30 & $6.3 \pm 0.6$ & $6.0 \pm 0.4$ & $5.6 \pm 0.4$ & $5.3 \pm 0.8$ & $4.5 \pm 0.5$ \\
\hline $\mathbf{t}$ & & 10.955 & 8.898 & 3.528 & 1.365 & 0.000 \\
\hline p & & 0.001 & 0.001 & 0.001 & 0.178 & 1.000 \\
\hline Inter-group comparison, $* p<0.05$
\end{tabular}

Under the stimulation of anesthesia, tube pulling, pain and surgery, renin angiotensin (RAS), aldosterone (ADS), epinephrine, cortisol and catecholamine (CA) secreted by the body will increase. The too high hormone level will stimulate stress response of the body, which is adverse to recover. ${ }^{12}$ The concentration of cortisol, epinephrine, norepinephrine and glucose is an important indicator to reflect stress intensity. ${ }^{13}$ Cortisol owns high sensitivity, and its level is closely related to stress response intensity and duration. The higher the cortisol level, the more arcuate the stress response. ${ }^{14}$ Internal and external stimulation of the body can cause sympathetic nerve excitation of the patients receiving gastrointestinal surgery, and result in serum CA level rise, the increase of serum cortisol, epinephrine and norepinephrine level, gluconeogenesis rise and glucose level rise. ${ }^{15}$ Senile patients are often combined with hypertension and other underlying diseases.
The resilience of their aorta and surrounding artery declines, and nervous system and blood vessel regulation capacity reduce. Under stress stimulation, their circulatory system compensation capacity weakens, and thus the occurrence rate of severe complications of heart, brain and kidney increases. ${ }^{16}$ This study showed that, serum epinephrine, norepinephrine, cortisol and glucose concentration of observation group declined to different degree after the surgery, indicating that preemptive analgesia effect of oxycodone hydrochloride can reduce patients' stress hormone level. This may be related to action, peak and hold time of oxycodone hydrochloride in the body of old people. Ligang et al. ${ }^{17}$ considered that, oxycodone relieved stress response caused in the rube pulling period and reduced serum epinephrine, and cortisol level. Moreover, oxycodone can make cortisol and testosterone drop, thus inhibiting overstress response caused by surgery and other 
stimulation. ${ }^{8}$ Some research shows that opioids restrain stress response of body through inhibiting secretion of adrenocorticotrophic hormone and $\beta$-endorphin or acting on stress hormone precursor. ${ }^{18}$ The literature indicates that oxycodone can well inhibit stress response level after the surgery. ${ }^{19}$ The above research results are close to this study.

Oxycodone hydrochloride owns double agonist effect of k-receptor and $\mu$-receptor, and is widely applied in postoperative analgesia. ${ }^{20}$ Its effect feature is similar to morphine. It can effectively restrain central nervous excitation through inhibiting peripheral nerve sensitivity, with very ideal analgesic effect. In this study, preemptive analgesia method was applied for the senile patients receiving gastrointestinal surgery. VAS score of the patients in the observation group significantly declined when the surgery was completed, $2 \mathrm{~h}$ and $6 \mathrm{~h}$ after the surgery. This proves that analgesic effect of oxycodone hydrochloride is obvious, and its timeliness may be related to half-life period of medicine.

\section{CONCLUSION}

Oxycodone hydrochloride preemptive analgesia can reduce the secretion of stress hormones and inhibit the occurrence of overstress reaction in elderly patients undergoing gastrointestinal surgery in a certain period of time, and has specific analgesic effect, with safety.

\section{ETHICAL APPROVAL:}

The study was approved by the Institutional Ethics Committee of Baoding First Central Hospital.

\section{PATIENTS' CONSENT:}

Written informed consents were obtained from all participants.

\section{CONFLICT OF INTEREST:}

The authors declare that there is no conflict of interest.

\section{AUTHORS' CONTRIBUTION:}

JZ, HY: Designed this study and prepared this manuscript.

YZ: Collected and analysed clinical data.

$\mathrm{KZ}$ : Significantly revised this manuscript.

\section{REFERENCES}

1. Liu MY, Tang HC, Hu SH, Chang SJ. Peptide-based enteral formula improves tolerance and clinical outcomes in abdominal surgery patients relative to a whole protein enteral formula. World J Gastrointest Surg 2016; 8:700-5.

2. Jinli Z, Hongli Y, Xiaoshi J, Jing Z. Influence of preemptive analgesia with parecoxib sodium on stress reaction and inflammation reaction in elderly patients after abdominal operation. $J$ of Hainan Medical University 2014; 20:854-6.

3. Lee JK, Chung KS, Choi $\mathrm{CH}$. The effect of asingle does of preemptive pregabalin administered with COX-2 inhibitor: A trial in total knee arthroplasty. J Arthroplasty 2014; 30:38-42.

4. Ben-Joseph R, Chen CC, De AP, Wade RL, Shah D. Consequences of patient access restrictions to branded oxycodone hydrchloride extend-er-lease tablets on heathcare utilization and costs in US health pians. J Med Econ 2014; 17:708-18.

5. Yan M. Interpretation of standardized treatment for cancer pain and 2010 guidelines of adult cancer pain clinical practice (Chinese edition). Modem practical Med 2012; 24:127-9.

6. Coldrey JC, Upton RN, Macintyre PE. Advances in analgesia in the older patient. Clin Anaesthesiol 2011; 25:367-78.

7. Beatty CW, Ko PR, Nixon J, Gospe SM Jr. Delayed-onset movement disorder and encephalopathy after oxycodone ingestion. Semin Pediatr Neurol 2014; 21:160-5.

8. Kucharz J, Filipczak-Bryniarska I, Michalowska-Kaczmarczyk A, Herman RM, Krzemieniecki K. Use of high-dose oxycodone hydrochloride in patients with visceral and neuropathic pain. Contemp Oncol 2015; 19:257-9.

9. Larochelle MR, Zhang F, Ross-Degnan D, Wharam JF. Rates of opioid dispensing and overdose after introduction of abuse-deterrent extended-release oxycodone and withdrawal of propoxyphene. JAMA Intern Med 2015; 175:978-87.

10. Bedirli N, Ak abay M, Emik U. Tramadol vs dexmedetomidine for emergence agitation control in pediatric patients undergoing adenotonsillectomy with sevoflurane anesthesia: BMC Anesthesiol 2017; 17:41.

11. Hu LG, Pan JH, Li J, Kang F, Jiang L. Effects of different doses of sufentanil and remifentanil combined with propofol in target-con-trolled infusion on stress reaction in eilerly patients. ExpTher Med 2013; 5:807-12.

12. Bollito E, Terrone C, Volpe A, Porpiglia F, Cracco C, Poggio M, et al. Changes in prostate cancer at radical prostatectomy during the prostate specific antigen era: An Italian experience. Anal Quant Cytol Histol 2008; 30:152-9.

13. Maya-Mendoza A, Ostrakova J, Kosar M, Hall A, Duskova P, Mistrik $M$, et al. Myc and Rasoncogenes engage different enery metabolism programs and evoke distinct patterns of oxidative and DNA replication stress. Mol Oncol 2015; 9(3):601-16.

14. Benda J. Impact of oxycodone on stress reaction during tracheal extubation and postoperative pain in patients undergoing laparoscopic cholecystectomy. J of Hepatobiliary Surgery 2017; 2:49.

15. Bulut T, Yilmazlar A, Yavascaoglucose B, Sarisozen B. The effect of local anaesthetic on post-operative pain with wound instillation via a catheter for paediatric extremity surgery. J Child Orthop 2011; 5:179-85.

16. Yupei G, Shouchun L, Hao W. Effects of oxycodone on hemodynamics and stress response during total anesthesia. Modern $\mathrm{J}$ of Integrated Traditional Chinese and Western Medicine 2016; 25:550.

17. Fang $T$, Changchun L, Yanhong C. Clinical observation of vital signs for elders with hypertension during analgesic gastroscopy. J Clin Res 2015; 32:461-462,466.

18. Lalovic B, Kharasch E, Hoffer C, Risler L, Liu-Chen LY, Shen DD. Pharmacoki-netics and pharmacodynamics of oral oxycodone in healthy human subjects: role of circulating active metabolites. Clin Pharmacol Ther 2013; 79:461-79.

19. Peckham EM, Traynor JR. Compararison of the antinoci-ceptive response to morphine and morphine-like compounds in male and female Sprague-Dawley rats. J Pharmacol ExpTher 2012; 316:1195-1201.

20. King SJ, Reid C, Forbes K, Hanks G. A systematic review of oxycodone in the management of cancer pain. Palliat Med 2011; 25:454-7. 